\title{
Experimental researches of plant protection means
}

\author{
Sergey V. Belousov ${ }^{1, *}$, and Anna I. Belousova ${ }^{1}$ \\ ${ }^{1}$ Federal State Budgetary Educational Institution of Higher Education "Kuban State Agrarian Univer- \\ sity named after I.T. Trubilin", Krasnodar, Russian Federation
}

\begin{abstract}
There was presented and investigated the problem of the application of atomizing tips in the system of processing plants with backpack sprayers in small forms of management and conditions of limited land use. Laboratory researches were conducted using the equipment of the company TeeJetTechnologies, namely for the work on the specified equipment there was designed the dispenser for the selection of atomizing tips of the present design of the sprayer. It will allow you to select atomizing tips for wider use. Also there were designed forms of tables to control the operation of the proposed sprayer based on the processing of one row.
\end{abstract}

Complex chemical protection of agricultural plants is now the main means of pest control, diseases and weeds. This is due to the fact that, despite the numerous methods, tools and techniques used to protect plants, losses from pests, diseases and weeds, according to leading organizations, in average amounts for $35 \%$, and in developing countries- up to $49 \%$. In our country, the average yield is up to $28 \%$, excluding losses [1].

Many edible plants synthesize and constantly contain small amounts of toxic chemical compounds in order to protect against insects and animals. However, some substances must be introduced in the process of growth, different types of sprayers are used for it. So, in most cases they are used in small forms of farming and small households. However, the treatment with such sprayers should be carried out several times per season, and it negatively affects the final quality of the product [2].

Chemicals can get in food as a result of processing of agricultural fields with mineral fertilizers, pesticides, during transportation, when using chemical additives to improve the appearance, commodity and other properties of products. There are cases of contamination of food by metal compounds and other elements - lead, arsenic, mercury, cadmium, tin, manganese, as well as petroleum products, pesticides, nitrate compounds.

In this situation, products that are grown in small farms and households are very popular among consumers than products of large agricultural producers. Production of small farms and households is more environmentally friendly as the farmer is ready to achieve the final goals with the lowest expenses and in the field of application of chemicals too [3].

Our main task is to optimize the processing of arable crops as in rows for feeding as in row spacing for weed control at the lowest costs. Currently, chemical weeding of row spacing of cultivated crops is widely applied. However, in the processing of objects, there is the

${ }^{*}$ Corresponding author: sergey_belousov_87@mail.ru 
demolition of the working fluid. Drops, which are subject to demolition, have a size of less than 200 microns and easily leave the working area during operation, and can fall into undesirable areas and cause serious consequences for the growth of crops [4].

A number of variables and non-permanent factors is influenced on the demolition of the working fluid at the time of treatment of cultivated plants: size of drop, height of the spraying, wind speed, temperature, humidity and atmospheric pressure. The main means of combating this problem is the use of special tips that are strictly oriented towards the treated surface. These accessories are working actively and allowing to supply the control of introduction mostly on straight sections, however, this factor is not constant throughout the rut and on the distortions we can observe gaps in this design.

The equipment provided by TeeJetTechnologies (the company is a leader in the production of components for accurate measurement, development and application of technology of control systems and data management) was used in laboratory researches. On Fig.1 there were shown the recommendations for the use of the atomizing tips of the same company.

To operate on the specified equipment there was designed and patented the construction of the sprayer to select the atomizing tips for the developed design of the sprayer. It will allow you to choose the atomizing tips for their wider use. Since the use of caps for modern knapsack sprayers is not possible, and the nomenclature range of the tips is currently very extensive, and the working range for their work can provide a knapsack sprayer, especially those structures that operate on autonomous power sources [5].

For convenience, let us set some final parameters:

1. The pressure that can develop a working knapsack sprayer reaches no more than 6 atm.

2. The speed at which the processing is carried out is no more than $7-8 \mathrm{~km} / \mathrm{h}$.

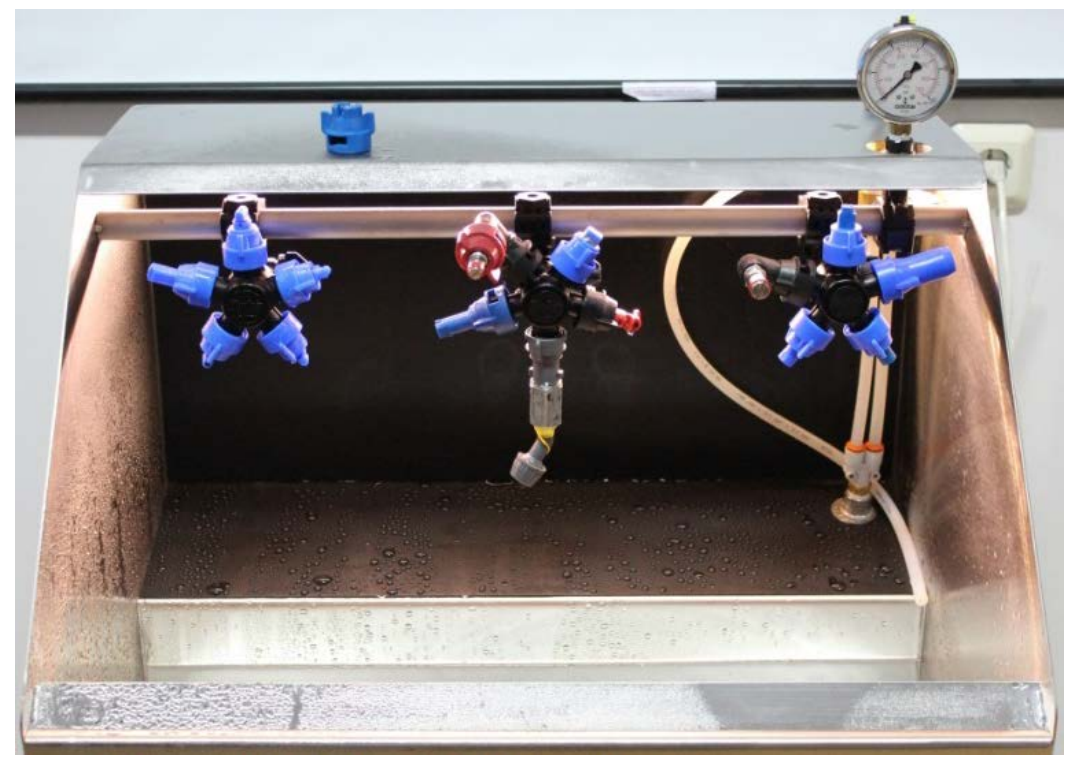

Fig. 1. Demonstration stand of the company TeeJetTechnologies

The choice of atomizing tips is determined according to the recommendations of the company for their working and physical capabilities, and the choice of the tip type is due to the conditions that are most often used in the designs of knapsack sprayers (Figure 2). 


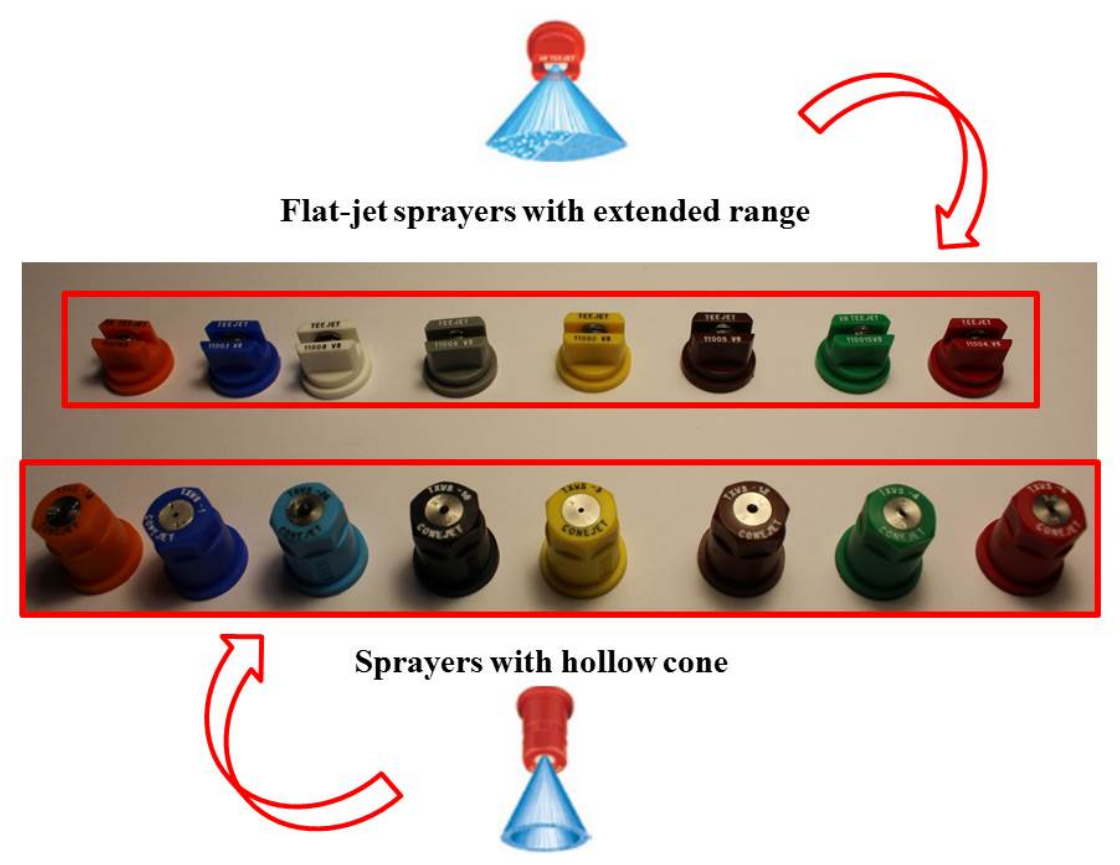

Fig. 2. Set of atomizing tips of the company TeeJetTechnologies used in the present research

The main design feature during laboratory researches is the universal case for the atomizing tip. It will make it possible to use not only the tips that come with the sprayer, but also to use more modern and perfect tips and thereby expand the range of use of portable sprayers [6].

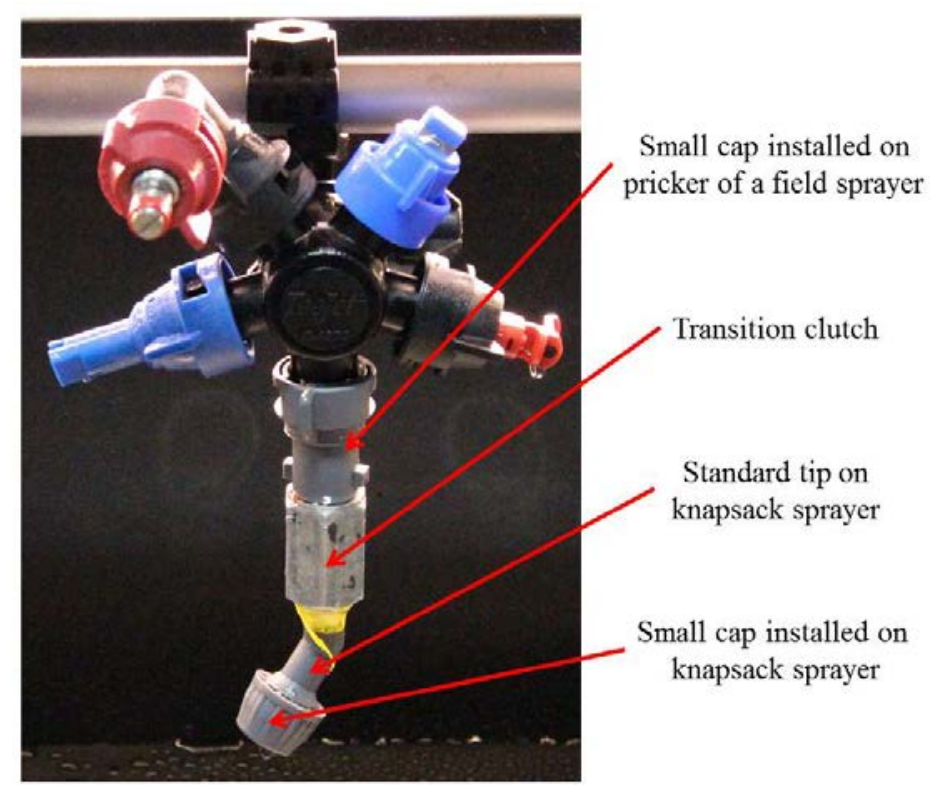

Fig. 3. Designed frame for sprayer for laboratory researches of existing tips 


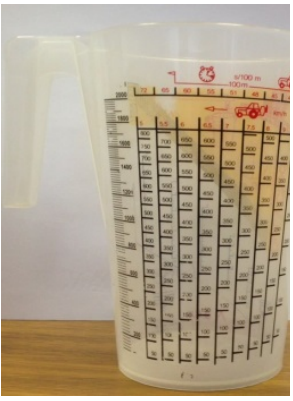

a

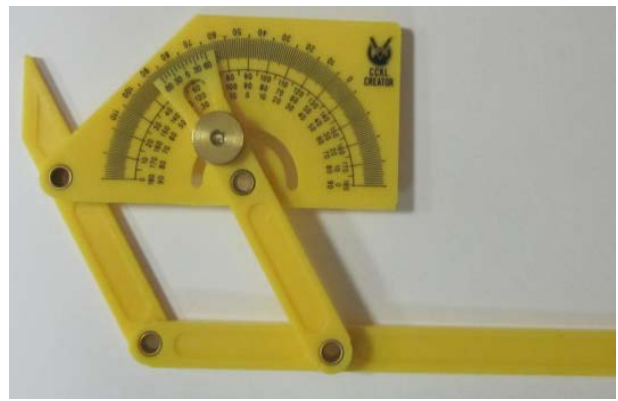

b

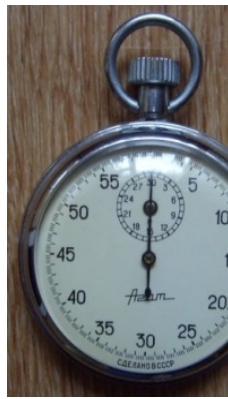

c

Fig. 4. Tools for laboratory researches. $\mathrm{a}$ - measuring container; $\mathrm{b}$ - goniometer; $\mathrm{c}-$ stopwatch.

The selected atomizing tips in their characteristics constructively and technically fully correspond to the operating pressure, which can provide a knapsack sprayer that has an active pressure discharge drive. In this regard, we were faced with the task to optimize the variety of atomizing tips according to the results of laboratory researches on the installation of TeeJetTechnologies [7].

For laboratory studies there have been developed and constructed a device to simulate the movement of the sprayer in spaces between rows and rows of cultivated crops (Figure $5)$. The given device will allow to explore the process of operation of the sprayer at different modes of movement [8].

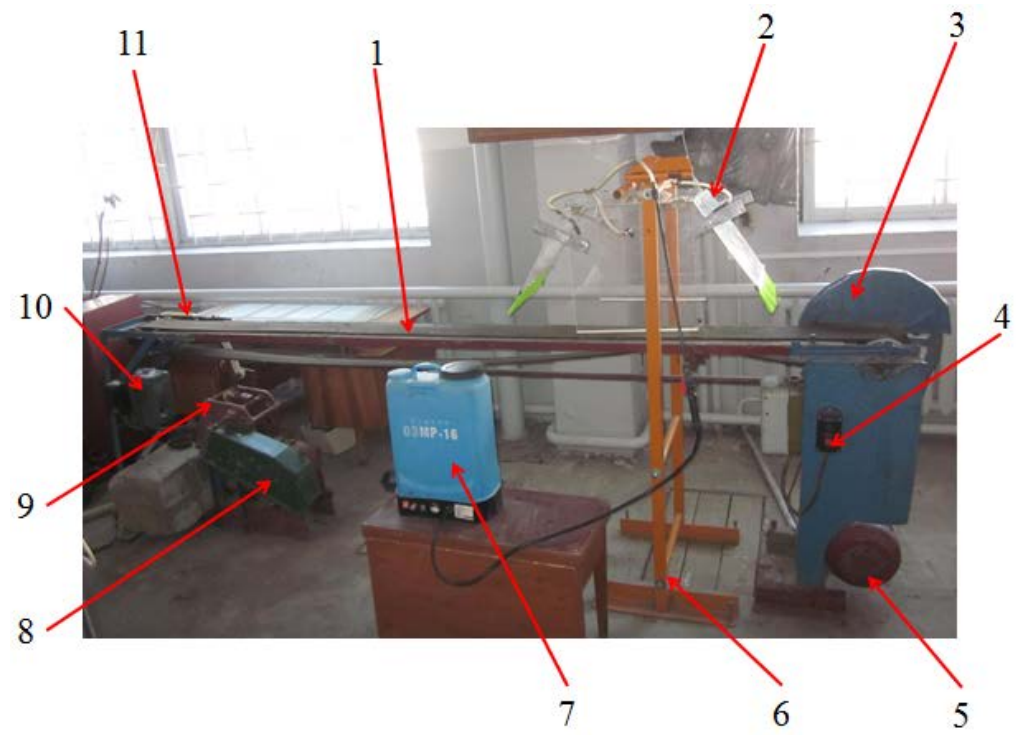

Fig. 5. Construction of the device to simulate the movement of the sprayer in spaces between rows and rows of cultivated crops

The design consists of 1 desktop, 2 working design of the sprayer, 3 pulley of working desktop drive, 4 starters, 5 electric motor, 6 mobile frame for adjustment of the working design of the sprayer, 7 rechargeable sprayer, 8 gearbox drive, 9 gearbox, 10 starter of electric motor of gearbox, 11 pulley of the drive of desktop from the gearbox. 
The process of work is as follows: the desktop moves both to the left and to the right by means of a drive or an electric motor through a large pulley which gives an average motion to the desktop with respect to the speed of the sprayer in the field, or from the electric motor, which drives the desktop through the gearbox, with a choice of a range of motion from $1-18 \mathrm{~km} / \mathrm{h}$. The movable frame serves for fixing the working design of the sprayer for treating plants that are installed on the desktop, it is also possible to install it at any place above the desktop [9].

There was obtained the design of the stand which will allow to carry out tests, independently on weather conditions and at various operating modes of different agricultural cars on the example of work of laboratory installation on research of indicators of the sprayer's work.

The article presents a constructive and technological scheme of the apparatus of complex processing of tilled crops, which allows to produce model experiments without depending on weather conditions.

The group of authors expresses the gratitude to TeeJetTechnologies namely its Krasnodar branch for providing the equipment for laboratory researches. The company TeeJetTechnologies and FSBEI PE Kuban State Agrarian University have friendly partnerships which are aimed at a closer link between science and production, and as a consequence the application of innovative products to the final producer of agricultural products.

\section{References}

1. E.I., Belousov S.V., Lepshina A.I. The results of experimental studies determine the degree of traction resistance of the plowshoe in the treatment of heavy soils, The political network electronic scientific journal of the Kuban State Agrarian University, No. 103, 673-686 (2014)

2. Belousov S.V., Lepshina A.I., Trubilin M.E. A plowshare plow for tillage with a turnover of the bed, Rural mechanic, No 3, 6-7 (2015)

3. Pomyelyko S.A., Belousov S.V. Single-row sprayer, Scientific provision of the agroindustrial complex. Collection of articles on the materials of the IX All-Russian Conference of Young Scientists. Responsible for the launch: A.G. Koshchaev, pp. 382-384. (2016)

4. Papusha S.K., Belousov S.V., Bogus A.E., Konovalov V.I. Theoretical studies of the tobacco stalk interaction with the leaf-separating unit, International Journal of Applied Engineering Research. -2016. -T. 11.-No. 8.-C. 5610-5613 (2016)

5. Belousov S.V. Patent search for structures that provide soil treatment with the turnover of the reservoir. Search method. The proposed technical solution, The political network electronic scientific journal of the Kuban State Agrarian University, No. 109, 416-450 (2015)

6. Belousov S.V. Means of minor mechanization, Scientific provision of the agroindustrial complex. Collection of articles on the materials of the IX All-Russian Conference of Young Scientists. Responsible for the issue: А.Г. Koshchayev pp. 315-316. (2016)

7. Palapin A.V., Belousov S.V., Modern approach to chemical plant protection, British Journal of Innovation in Science and Technology, T. 1., № 3, 13-24 (2016)

8. Belousov S.V., Belousova A.I. Method for processing experimental data as a result of agricultural tests, British Journal of Innovation in Science and Technology, T. 2, No. 5, 29-39. (2017) 
9. Lepshina A.I., Belousov S.V. Means of minor mechanization as the basis of modern peasant farms and small farms in small forms of management, A political online scientific journal of the Kuban State Agrarian University, No. 109, 392-415 (2015) 